\title{
Short Term Operative Outcomes of Laparoscopic Gastric Mobilization in Esophagectomy for Esophageal Cancer: Comparison with Hand Assisted Technique
}

\author{
Masashi Takemura*, Mamiko Takii, Nobuaki Kaibe, Tsutomu Oshima, Mitsuru Sasako \\ Department of Upper Gastrointestinal Surgery, Hyogo College of Medicine, Hyogo, Japan \\ Email: "mtake@hyo-med.ac.jp
}

Received 16 March 2016; accepted 18 June 2016; published 21 June 2016

Copyright (C) 2016 by authors and Scientific Research Publishing Inc.

This work is licensed under the Creative Commons Attribution International License (CC BY).

http://creativecommons.org/licenses/by/4.0/

(c) (i) Open Access

\begin{abstract}
Objective: This study evaluated the safety and operative utilities of the laparoscopic gastric mobilization compared with hand-assisted laparoscopic gastric mobilization. Patients and Methods: From April 2010 to November 2015, 125 patients with esophageal cancer have been performed laparoscopic mobilization; 33 under hand-assisted laparoscopic gastric mobilization (HLG group) and 92 under laparoscopic gastric mobilization without hand-assisted technique (LG group). Preoperative data and surgical outcomes of 2 groups were compared. Results: Preoperative data were not significantly different except for BMI. Operation time in abdominal procedure of LG group is significantly longer than HLG group $(P<\mathbf{0 . 0 0 0 1})$. Otherwise, the blood loss and number of dissected nodes of abdominal procedure was not significantly different in two groups. The perioperative blood transfusions were needed in 7 cases $(21.2 \%)$ in HLG group and $25(27.1 \%)$ in LG group. The postoperative complications and mortality within 30 days after surgery were not significantly different in two groups. The length of hospital stay was 29 days in HLG group and 31 days in HG group, respectively. Conclusions: Our results suggested that laparoscopic gastric mobilization was safe technique and the short-term operative outcomes were comparable with that of hand-assisted laparoscopic mobilization.
\end{abstract}

\section{Keywords}

Laparoscopic Gastric Mobilization, Minimally Invasive Esophagectomy, Esophageal Cancer

\footnotetext{
${ }^{*}$ Corresponding author.
}

How to cite this paper: Takemura, M., Takii, M., Kaibe, N., Oshima, T. and Sasako, M. (2016) Short Term Operative Outcomes of Laparoscopic Gastric Mobilization in Esophagectomy for Esophageal Cancer: Comparison with Hand Assisted Technique. Surgical Science, 7, 279-285. http://dx.doi.org/10.4236/ss.2016.77039 


\section{Introduction}

Esophagectomy combined thoracotomy with laparotomy for esophageal cancer is associated with high rate of morbidity and mortality because of high invasive surgical procedure [1] [2]. So, minimally invasive esophagectomy (MIE), included thoracic esophagectomy with mediastinal lymph node dissection under thoracoscopy and gastric mobilization with abdominal lymph node dissection under laparoscopy, have been widely recognized due to less postoperative wound pain and early recovery from postoperative status [3]-[6]. However, many clinical questions about MIE are still debated because of lack of randomized study compared with open surgery.

In the abdominal part of esophagectomy, several authors described the clinical utilities of hand-assisted laparoscopic gastric mobilization, such as less blood loss and low incidence of postoperative pneumonia [7] [8]. However, few reports about clinical utilities laparoscopic gastric mobilization without hand-assisted technique were shown [9]-[11].

We have adopted thoracoscopic esophagectomy in left lateral decubitus position with artificial pneumothorax for esophageal cancer from April 2010 [12]. At the time of introducing of thoracoscopic esophagectomy, we have also introduced hand-assisted laparoscopic gastric mobilization (HLG). However, hand-assisted technique required the small laparotomy tailored to each operator's hand size. Therefore, we improved the laparoscopic gastric mobilization without hand-assisted technique (LG) from December 2012 for the purpose of less surgical trauma. The aim of this study was to evaluate the safety and short-term operative outcomes of LG compared with HLG.

\section{Patients and Methods}

From April 2010 to November 2015, thoracoscopic esophagectomy have been indicated in 140 patients with esophageal cancerin our department. In these patients, laparoscopic gastric mobilization has been performed in 125 (89\%). Our indications of laparoscopic gastric mobilization are patients with no previous abdominal operation and using gastric tube for esophageal substitute. These patients were divided into two groups chronologically; 33 patients who performed hand-assisted laparoscopic gastric mobilization were classified in HLG group and 92 patients who performed laparoscopic gastric mobilization were classified in LG group. The patients' clinical records were reviewed to analysis preoperative data between two groups. Operative time, estimated blood loss, number of harvested lymph node and blood transfusion required were collected based on operation records. The duration of hospital stay after surgery, mortality and major morbidity, such as anastomotic leakage, respiratory failure and hemorrhage, were compared. The pathological stage was described according to Japanese classification of esophageal cancer [13] [14].

Our technique of thoracoscopic esophagectomy under left lateral decubitus position with artificial pneumothorax and its clinical utilities have been well documented previously [12]. Our procedure of laparoscopic gastric mobilization and abdominal lymphadenectomy are as follows. The patients were positioned in a 20-degree anti Trendelenburg and split leg position with the operating surgeon on the right side of the patients, the first assistant surgeon on the left, and camera assistant in the middle. Under general anesthesia, a 10-mmHg pneumoperitoneum is induced by a $12-\mathrm{mm}$ trocar at the umbilicus via the open technique. Additional 5 trocars using three 5-mm trocar and two 12-mm trocars were introduced for access the abdominal cavity (Figure 1). The lateral lobe of the liver was retracted upward using Silicone Disk method described previously [15].

At first, the lesser omentum is divided along the attached point of the liver toward the diaphragmatic hiatus. The stomach is pulled up with atraumatic instruments and retrogastric tissues are divided. The lymph node along the common hepatic artery, the celiac axis and proximal splenic artery were dissected along each artery. The left gastric vein divided, and the left gastric artery were exposed and double clipped with dissection of the left gastric artery lymph nodes toward the right crus of the esophageal hiatus.

After drawing the isolated thoracic esophageal specimen with dissected thoracic lymph nodes through esophageal hiatus, short gastric vessels were divided from cranial side the splenic hilum toward the left gastroepiloic vessels. The esophageal hilum was closed by running suture using V-loc wound closure device (Covidien, Norwalk, CT, USA).

The greater omentum was divided along $3 \mathrm{~cm}$ from the gastroepiploic arcade using ultra sonic scalpel (Echicon EndoSurgery Inc, Cincinnati, OH, USA). After the left gastroepiploic vessels were divided, we turned backward to the right gastroepiploic vessels and carefully preserved. We do not perform the pyloroplasty and Kocher maneuver. 


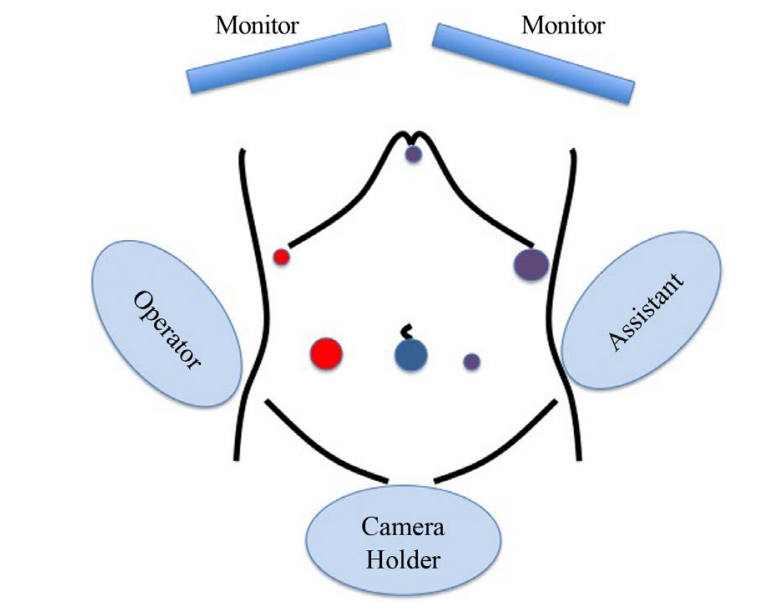

Figure 1. Trocars location of laparoscopic gastricmobilization.

Gastric conduit of $3 \mathrm{~cm}$ in width was created outside a $4 \mathrm{~cm}$ upper midline skin incision. The lesser curvature was skeletonized in preparation for stapling. The first stapler, curved linear 60-mm endostapler (Covidien, Norwalk, CT, USA), was fired just below the angle of the lesser curvature. Then, three or four additional staplings were performed paralleled the greater curvature. The gastric tube was pulled up gently through the retrosternal route. Esophago-gastric anastomosis was performed by end to end fashion with our original modified trianglestapling technique [16].

\section{Statistical Analysis}

The Mann-Whitney U test was used to analyze the correlations among the continuous variables for each group. The Pearson chi-squared test was applied to qualitative variables. P values $<0.05$ were considered significance. Data analysis was performed using Graph Pad Prism 6 for Mac OS X.

\section{Results}

Clinical characteristics and operative outcomes of each group were shown in Table 1 . There were no significant differences in preoperative characteristics including age, gender and ASA score, between two groups. Preoperative BMI was significantly lower in LG group $(P=0.0194)$. One case of HLG group was converted to open surgery and 1 case of LG group was converted to hand-assisted laparoscopic technique, respectively. Total and abdominal operation times were significantly longer in LG group $(\mathrm{P}=0.0121$ and $\mathrm{P}<0.0001)$. Otherwise, the estimated blood loss and harvested lymph nodes in abdominal part of esophagectomy were not different.

The cases that required perioperative blood transfusion were 7 in HLG group (21.2\%) and 25 in LG group (27.2\%), respectively. The rate of postoperative complications, such as anastomotic leakage, pneumonia and surgical site infection, revealed no significantly different between 2 groups. The length of hospital stay was 29 days in HLG group and 31 days in LG group $(\mathrm{P}=0.7643)$.

\section{Discussion}

Although, esophagectomy with extended lymph node dissection and reconstruction is highly complex associated with significant postoperative complications, this procedure is widely recommended for curative intent for resectable esophageal cancer [1] [2]. Abdominal part of esophagectomy for esophageal cancer includes gastric mobilization with abdominal lymphadenectomy and creating esophageal conduit. Conventionally, gastric mobilization was performed under laparotomy. However, laparotomy related decreased QOL, high rate of surgical site infection and less cosmetic results. To solve these problems, laparoscopic procedure was proposed as an alternative choice for abdominal part of esophagectomy.

Laparoscopic operation has been widely recommended various gastrointestinal diseases with the development of surgical instruments and laparoscopic optical devices. The laparoscopic procedure could improve the postoperative clinical course, reduces the incidence of postoperative pneumonia and surgical site infection compared 
Table 1. Characteristics of the patients.

\begin{tabular}{|c|c|c|c|c|}
\hline & & HLG & LG & $P$ value \\
\hline Number of cases & & 33 & 92 & \\
\hline Gender & Male:Female & 28:5 & $71: 21$ & 0.4568 \\
\hline Age & & $69(51-76)$ & $67(48-86)$ & 0.8738 \\
\hline Body mass index & & $21.9(14.9-33.3)$ & $20.7(15.2-27.8)$ & 0.0194 \\
\hline Location of tumors & U:M:L & $4: 22: 7$ & $15: 60: 17$ & 0.8262 \\
\hline Preoperative therapy & & 17 & 58 & 0.1562 \\
\hline ASA Score & $1: 2: 3$ & $0: 23: 10$ & $8: 64: 20$ & 0.1463 \\
\hline Pathological Stage & 0:I:II:III:IV & $0: 9: 12: 7: 5$ & 7:7:35:32:11 & 0.8282 \\
\hline Operation time (Total) & (minute) & $433(327$ - 1085) & $471(240$ - 1185) & 0.0121 \\
\hline Blood loss (Total) & $(\mathrm{ml})$ & $300(10-1150)$ & $210(5-2415)$ & 0.0490 \\
\hline Operation time (abdomen) & (minute) & $61(29-152)$ & $96(24-249)$ & $<0.0001$ \\
\hline Blood loss (abdomen) & $(\mathrm{ml})$ & $146(5-950)$ & $110(5-2265)$ & 0.0975 \\
\hline Dissected node (Total) & & $30(11-106)$ & $41(11-115)$ & 0.0080 \\
\hline Dissected node (abdomen) & & $18(1-42)$ & $17(1-50)$ & 0.7304 \\
\hline Conversion & & 1 & 1 & 0.4599 \\
\hline Blood transfuseon & & $7(21.2 \%)$ & $25(27.2 \%)$ & 0.6432 \\
\hline \multirow[t]{3}{*}{ Complication } & Leak & $8(24.2 \%)$ & $10(10.8 \%)$ & 0.0820 \\
\hline & Pneumonia & 3 & 11 & 0.7591 \\
\hline & SSI & 2 & 3 & 0.6068 \\
\hline Mortality (within 30 days) & & 1 & 2 & 1.0000 \\
\hline Hospital stay & (Days) & $29(16-307)$ & $31(6-202)$ & 0.7643 \\
\hline
\end{tabular}

U: Upper thoracic, M: Middle thoracic, L: Lower thoracic.

with open procedure [17] [18]. Furthermore, laparoscopic procedure is able to protect the gut drying and reduce the abdominal well trauma [19]. From these clinical benefits, the indications of laparoscopic procedure have been extended the several gastrointestinal diseases. In esophagectomy for esophageal cancer, several minimally invasive approaches have been described so far. Osugi $\mathrm{H}$ et al. reported the clinical benefits of thoracoscopic esophagectomy with mini thoracotomy followed by gastric mobilization under laparotomy [20]. They concluded that thoracoscopic esophagectomy can reduce the postoperative pulmonary dysfunction and potentially reduces morbidity than the open operation. Hsu PK et al. described that perioperative benefit of thoracoscopic esophagectomy included fewer postoperative complications and shorter ICU stays [21]. Furthermore, few randomized study of comparison minimally invasive esophagetomy with open esophagectomy has been reported [2] [4]. MIRO-trial shows the minimally invasive esophagectomy related to lower intraoperative blood loss, lower pulmonary complication and less wound pain. However, the operation time of minimally invasive technique is significantly longer than that of open procedure, and mortality is not significantly different in two procedures. In Japanese nationwide study, the minimally invasive esophagectomy related longer operation time and less blood loss [22]. However, incidence of anastomotic leakage and reoperation rate within 30 days were significantly higher in the minimally invasive esophagectomy than in the open esophagectomy. For the time being, the advantages of minimally invasive technique in esophagectomy over open surgery are still debatable.

In Japan, abdominal part of esophagectomy is performed conventional laparotomy or hand-assisted laparoscopic technique in many institutions [5] [8]. Clinical benefits of hand-assisted laparoscopic gastric mobilization over open surgery have been demonstrated in some reports. Oshikiri et al. reported that HALS had advantages in terms of less-restrictive ventilatory improvement, fewer subsequent pulmonary complications and less blood 
Table 2. Previous reports of laparoscopic gastricmobilization.

\begin{tabular}{cccccc}
\hline No & Author & Year & Number of patients & Operation time (min) & Estimated blood loss (ml) \\
\hline 1 & Kitagawa & 2006 & 45 & 570 (Total) & $430(190-1260)$ \\
2 & Bersadola & 2013 & 14 & ND & ND \\
3 & Lee JW & 2015 & 54 & $90.6 \pm 27.6$ & $460.0 \pm 355.5$ \\
\hline Blood transfusion & Conversion & $\begin{array}{c}\text { Perioperative } \\
\text { complication }\end{array}$ & Hospital stay (days) & Leakage & Mortality \\
\hline $9(20.0 \%)$ & 1 & 6 & $35(16-114)$ & $19.1 \%$ & ND \\
$1.57 \pm 1.82$ (Unit) & 0 & $6(37.6 \%)$ & $16.38 \pm 8.35$ & 1 & $3(5.6 \%)$ \\
$6(11.1 \%)$ & 0 & $13(24.1 \%)$ & $16.7 \pm 12.8$ & 2 & \\
\hline
\end{tabular}

ND: Not described.

loss [8]. In French nationwide study, laparoscopic gastric mobilization in esophagectomy is significantly reduced the postoperative mortality than open gastric mobilization [23]. Usually, laparoscopic procedure related to less trauma and low blood loss in spite of longer operation time. The amount of estimated blood loss closely related to the perioperative blood transfusion. The allogenic blood transfusion is obvious risk factor of worse prognosis and postoperative infectious complications [24] [25]. So, minimally invasive technique in esophagectomy may improve a prognosis of esophageal cancer from the perspective of avoidance of allogenic blood transfusion.

On the other hand, few reports described about clinical benefits of total laparoscopic gastric mobilization (Table 2). Lee JW reported the comparison of surgical outcomes in total laparoscopic gastroplasty with that of open method [10]. They showed that the postoperative complications and hospital stay were most significantly different between two groups. Kitagawa $\mathrm{H}$ et al. reported the technical feasibility of esophagectomy with regional lymphadenectomy combined with total laparoscopic gastric mobilization [9]. They reported that the operation time in abdominal stage of total laparoscopic gastric mobilization is longer than that of open procedure, ICU stay is shorter and postoperative pulmonary function was well preserved in total laparoscopic gastric mobilization. Total laparoscopic gastric mobilization have many clinical advantages over open procedure, such as less surgical trauma, decreased pulmonary dysfunction and shorter ICU stay. However none the report have been described the surgical outcomes of laparoscopic gastroplasty compared with that of hand-assisted laparoscopic gastroplasty so far. Our study shows the clinical outcomes of LG were comparable with that of hand-assisted technique except for longer operation time. In this reason, the LGM was adopted the standard surgical procedure in minimally invasive operation for esophageal cancer in our institution.

\section{Conclusion}

Our results suggested that the short-term clinical and surgical outcomes of laparoscopic gastric mobilization were comparable with that of hand-assisted technique. However, there is no clear evidence of clinical advantages of laparoscopic gastric mobilization because of lack of randomized study.

\section{References}

[1] Raymond, D. (2012) Complications of Esophagectomy. Surgical Clinics of North America, 92, 1299-1313. http://dx.doi.org/10.1016/j.suc.2012.07.007

[2] Parekh, K. and Iannettoni, M.D. (2007) Complications of Esophageal Resection and Reconstruction. Seminars in Thoracic and Cardiovascular Surgery, 19, 79-88. http://dx.doi.org/10.1053/j.semtcvs.2006.11.002

[3] Briez, N., Piessen, G., Bonnetain, F., et al. (2011) Open versus Laparoscopically-Assisted Oesophagectomy for Cancer: A Multicentre Randomised Controlled Phase III Trial-The MIRO Trial. BMC Cancer, 11, 310. http://dx.doi.org/10.1186/1471-2407-11-310

[4] Cuesta, M.A., Biere, S.S., van Berge Henegouwen, M.I. and van der Peet, D.L. (2012) Randomised Trial, Minimally Invasive Oesophagectomy versus Open Oesophagectomy for Patients with Resectable Oesophageal Cancer. Journal of Thoracic Disease, 4, 462-464. 
[5] Osugi, H., Takemura, M., Higashino, M., et al. (2003) A Comparison of Video-Assisted Thoracoscopic Oesophagectomy and Radical Lymph Node Dissection for Squamous Cell Cancer of the Oesophagus with Open Operation. British Journal of Surgery, 90, 108-113. http://dx.doi.org/10.1002/bjs.4022

[6] Guo, W., Ma, X., Yang, S., et al. (2015) Combined Thoracoscopic-Laparoscopic Esophagectomy versus Open Esophagectomy: A Meta-Analysis of Outcomes. Surgical Endoscopy, 1-9. http://dx.doi.org/10.1007/s00464-015-4692-x

[7] Yamasaki, M., Miyata, H., Fujiwara, Y., et al. (2011) Minimally Invasive Esophagectomy for Esophageal Cancer: Comparative Analysis of Open and Hand-Assisted Laparoscopic Abdominal Lymphadenectomy with Gastric Conduit Reconstruction. Journal of Surgical Oncology, 104, 623-628. http://dx.doi.org/10.1002/jso.21991

[8] Oshikiri, T., Yasuda, T., Kawasaki, K., et al. (2016) Hand-Assisted Laparoscopic Surgery (HALS) Is Associated with Less-Restrictive Ventilatory Impairment and Less Risk for Pulmonary Complication than Open Laparotomy in Thoracoscopic Esophagectomy. Surgery, 159, 459-466. http://dx.doi.org/10.1016/j.surg.2015.07.026

[9] Kitagawa, H., Namikawa, T., Iwabu, J., et al. (2013) Efficacy of Laparoscopic Gastric Mobilization for Esophagectomy: Comparison with Open Thoraco-Abdominal Approach. Journal of Laparoendoscopic \& Advanced Surgical Techniques, 23, 452-455. http://dx.doi.org/10.1089/lap.2012.0377

[10] Lee, J.W., Sung, S.W., Park, J.K., et al. (2015) Laparoscopic Gastric Tube Formation with Pyloromyotomy for Reconstruction in Patients with Esophageal Cancer. The Annals of Surgical Treatment and Research, 89, 117-123. http://dx.doi.org/10.4174/astr.2015.89.3.117

[11] Bresadola, V., Terrosu, G., Cojutti, A., et al. (2006) Laparoscopic versus Open Gastroplasty in Esophagectomy for Esophageal Cancer: A Comparative Study. Surgical Laparoscopy, Endoscopy \& Percutaneous Techniques, 16, 63-67. http://dx.doi.org/10.1097/00129689-200604000-00001

[12] Takemura, M., Hori, T. and Fujiwara, Y. (2013) Clinical Outcomes and Prognosis after Thoracoscopic Esophagectomy with Two-Field Lymph Node Dissection for Lower Thoracic Esophageal Cancer. Anticancer Research, 33, 601-608.

[13] Japan Esophageal Society (2009) Japanese Classification of Esophageal Cancer, Tenth Edition: Part I. Esophagus, 6, 1-25. http://dx.doi.org/10.1007/s10388-009-0169-0

[14] Japan Esophageal Society (2009) Japanese Classification of Esophageal Cancer, Tenth Edition: Parts II and III. Esophagus, 6, 71-94. http://dx.doi.org/10.1007/s10388-009-0193-0

[15] Takemura, M., Ikebe, T., Mayumi, K., et al. (2011) A Novel Liver Retraction Technique for Lateral Lobe of the Liver during Laparoscopic Surgery Using Silicone Disk. Journal of Laparoendoscopic \& Advanced Surgical Techniques, 21, 729-732. http://dx.doi.org/10.1089/lap.2011.0161

[16] Takemura, M., Yoshida, K. and Fujiwara, Y. (2013) Modified Triangulating Stapling Technique for Esophagogastrostomy after Esophagectomy for Esophageal Cancer. Surgical Endoscopy, 27, 1249-1253. http://dx.doi.org/10.1007/s00464-012-2586-8

[17] Inokuchi, M., Sugita, H., Otsuki, S., et al. (2015) Laparoscopic Distal Gastrectomy Reduced Surgical Site Infection as Compared with Open Distal Gastrectomy for Gastric Cancer in a Meta-Analysis of Both Randomized Controlled and Case-Controlled Studies. International Journal of Surgery, 15, 61-67. http://dx.doi.org/10.1016/j.ijsu.2015.01.030

[18] Coccolini, F., Catena, F., Pisano, M., et al. (2015) Open versus Laparoscopic Cholecystectomy in Acute Cholecystitis. Systematic Review and Meta-Analysis. International Journal of Surgery, 18, 196-204. http://dx.doi.org/10.1016/j.ijsu.2015.04.083

[19] Tittel, A., Schippers, E., Grablowitz, V., et al. (1995) Intraabdominal Humidity and Electromyographic Activity of the Gastrointestinal Tract. Laparoscopy versus Laparotomy. Surgical Endoscopy, 9, 786-790. http://dx.doi.org/10.1007/BF00190082

[20] Osugi, H., Takemura, M., Higashino, M., et al. (2002) Video-Assisted Thoracoscopic Esophagectomy and Radical Lymph Node Dissection for Esophageal Cancer. A Series of 75 Cases. Surgical Endoscopy and Other Interventional Techniques, 16, 1588-1593. http://dx.doi.org/10.1007/s00464-002-9019-z

[21] Hsu, P.K., Huang, C.S., Wu, Y.C., et al. (2014) Open versus Thoracoscopic Esophagectomy in Patients with Esophageal Squamous Cell Carcinoma. World Journal of Surgery, 38, 402-409. http://dx.doi.org/10.1007/s00268-013-2265-5

[22] Takeuchi, H., Miyata, H., Gotoh, M., et al. (2014) A Risk Model for Esophagectomy Using Data of 5354 Patients Included in a Japanese Nationwide Web-Based Database. Annals of Surgery, 260, 259-266. http://dx.doi.org/10.1097/SLA.0000000000000644

[23] Messager, M., Pasquer, A., Duhamel, A., et al. (2015) Laparoscopic Gastric Mobilization Reduces Postoperative Mortality after Esophageal Cancer Surgery: A French Nationwide Study. Annals of Surgery, 262, 817-823. http://dx.doi.org/10.1097/SLA.0000000000001470

[24] Takemura, M., Osugi, H., Takada, N., et al. (2003) Immunologic Effects of Allogeneic versus Autologous Blood 
Transfusion in Patients Undergoing Radical Oesophagectomy. European Surgical Research, 35, 115-122. http://dx.doi.org/10.1159/000070025

[25] Takemura, M., Osugi, H., Higashino, M., et al. (2005) Effect of Substituting Allogenic Blood Transfusion with Autologous Blood Transfusion on Outcomes after Radical Oesophagectomy for Cancer. Annals of Thoraacic and Cardiovascular Surgery, 11, 293-300.

\section{Submit or recommend next manuscript to SCIRP and we will provide best service for you:}

Accepting pre-submission inquiries through Email, Facebook, Linkedin, Twitter, etc A wide selection of journals (inclusive of 9 subjects, more than 200 journals)

Providing a 24-hour high-quality service

User-friendly online submission system

Fair and swift peer-review system

Efficient typesetting and proofreading procedure

Display of the result of downloads and visits, as well as the number of cited articles

Maximum dissemination of your research work

Submit your manuscript at: http://papersubmission.scirp.org/ 